\title{
Interaction of the Pseudomonas aeruginosa Secretory Products Pyocyanin and Pyochelin Generates Hydroxyl Radical and Causes Synergistic Damage to Endothelial Cells
}

\author{
Implications for Pseudomonas-associated Tissue Injury
}

\author{
Bradley E. Britigan, ** Tedmund L. Roeder, ${ }^{\star}$ George T. Rasmussen, ${ }^{\star}$ D. Michael Shasby, ${ }^{\star *}$ \\ Michael L. McCormick, ${ }^{\star}$ and Charles D. Cox ${ }^{5}$ \\ Research Service and Department of Internal Medicine, VA Medical Center, Iowa City, Iowa 52246; and Departments of ${ }^{\ddagger}$ Internal \\ Medicine and ${ }^{\S}$ Microbiology, University of Iowa College of Medicine, Iowa City, Iowa 52242
}

\begin{abstract}
Pyocyanin, a secretory product of Pseudomonas aeruginosa, has the capacity to undergo redox cycling under aerobic conditions with resulting generation of superoxide and hydrogen peroxide. By using spin trapping techniques in conjunction with electron paramagnetic resonance spectrometry (EPR), superoxide was detected during the aerobic reduction of pyocyanin by NADH or porcine endothelial cells. No evidence of hydroxyl radical formation was detected. Chromium oxalate eliminated the EPR spectrum of the superoxide-derived spin adduct resulting from endothelial cell exposure to pyocyanin, suggesting superoxide formation close to the endothelial cell plasma membrane. We have previously reported that iron bound to the $P$. aeruginosa siderophore pyochelin (ferripyochelin) catalyzes the formation of hydroxyl free radical from superoxide and hydrogen peroxide via the Haber-Weiss reaction. In the present study, spin trap evidence of hydroxyl radical formation was detected when NADH and pyocyanin were allowed to react in the presence of ferripyochelin. Similarly, endothelial cell exposure to pyocyanin and ferripyochelin also resulted in hydroxyl radical production which appeared to occur in close proximity to the cell surface. As assessed by ${ }^{51} \mathrm{Cr}$ release, endothelial cells which were treated with pyocyanin or ferripyochelin alone demonstrated minimal injury. However, endothelial cell exposure to the combination of pyochelin and pyocyanin resulted in $55 \%$ specific ${ }^{51} \mathrm{Cr}$ release. Injury was not observed with the substitution of iron-free pyochelin and was diminished by the presence of catalase or dimethyl thiourea. These data suggest the possibility that the $\boldsymbol{P}$. aeruginosa secretory products pyocyanin and pyochelin may act synergistically via the generation of hydroxyl radical to damage local tissues at sites of pseudomonas infection. (J. Clin. Invest. 1992. 90:2187-2196.) Key words: free radical • iron • pyocyanin • siderophore $\bullet$ spin trap • superoxide
\end{abstract}

This work was presented in part on 2 October 1991 at the Interscience Conference of Antimicrobial Agents and Chemotherapy in Chicago, IL.

Address reprint requests to Dr. Britigan, Department of Internal Medicine, SW54, GH, University of Iowa College of Medicine, Iowa City, IA 52246. 1992.

Received for publication 22 April 1992 and in revised form 22 July

The Journal of Clinical Investigation, Inc.

Volume 90, December 1992, 2187-2196

\section{Introduction}

Nosocomial pneumonia remains a major cause of morbidity and mortality in the United States. In most clinical series Pseudomonas aeruginosa ranks among the top three Gram-negative organisms causing such infections (1). Pseudomonas pneumonia is particularly severe with a mortality approaching $70 \%$ even with appropriate antibiotic therapy $(1,2) . P$. aeruginosa also plays a major role in the chronic progressive pulmonary dysfunction in patients with cystic fibrosis, which is manifested as progressive bronchiectasis and hemoptysis (3) and which currently accounts for $>90 \%$ of deaths in these patients (4). It is unclear why Pseudomonas lung infections carry such a high fatality rate. Most work has focused on the destructive nature of Pseudomonas-derived proteases and other toxins $(2,4)$. However, alternative mechanisms may be involved.

Many $P$. aeruginosa strains secrete pyocyanin, a phenazine derivative (5-methyl-1-hydroxyphenazine), which is toxic for eukaryotic and prokaryotic cells (5-7). Wilson et al. (8) reported that pyocyanin, at concentrations present in the sputum sol of cystic fibrosis patients, induced ciliary dysfunction in human nasal epithelial cells $(9,10)$. Like paraquat, menadione, and other xenobiotics, pyocyanin can redox cycle in the presence of various reducing agents and oxygen with resultant formation of superoxide $\left({ }^{\circ} \mathrm{O}_{2}^{-}\right)$and hydrogen peroxide $\left(\mathrm{H}_{2} \mathrm{O}_{2}\right)$ (5). Pyocyanin-induced free radical production appears to be responsible for much of its microbicidal activity (5), but its role in $P$. aeruginosa-associated tissue injury is less clear.

Superoxide and $\mathrm{H}_{2} \mathrm{O}_{2}$ are only moderately reactive oxidants. In the presence of an exogenous iron catalyst, ${ }^{\circ} \mathrm{O}_{2}^{-}$and $\mathrm{H}_{2} \mathrm{O}_{2}$ react to form hydroxyl radical via the Haber-Weiss reaction (11). This extremely reactive and toxic oxidant has been incriminated as the actual mediator of several forms of cell injury associated with ${ }^{\circ} \mathrm{O}_{2}^{-} / \mathrm{H}_{2} \mathrm{O}_{2}$ exposure (12). In vivo, extracellular iron is tightly complexed to host iron-binding proteins such as transferrin and lactoferrin. These iron chelates cannot participate in the Haber-Weiss reaction (13-15), thereby protecting tissue from the potentially damaging effects of untoward hydroxyl radical formation (16). Although some intracellular iron chelates such as ferritin and haemosiderin have been reported to be capable of acting as hydroxyl radical catalysts $(17,18)$, the presence of intracellular antioxidants such as the superoxide dismutases and catalase limit the access of ${ }^{\circ} \mathrm{O}_{2}^{-}$ and $\mathrm{H}_{2} \mathrm{O}_{2}$ to them. This suggests that pathologic in vivo hydroxyl radical generation may sometimes depend on the presence of nonphysiologic iron chelates.

Like many microorganisms, $P$. aeruginosa secretes ironbinding compounds (siderophores) which allow the organism 
to compete with host iron-binding proteins for iron $(19,20)$. Recently, we found that iron bound to the $P$. aeruginosa siderophore pyochelin was capable of catalyzing the formation of hydroxyl radical from a continuous flux of ${ }^{\circ} \mathrm{O}_{2}^{-} / \mathrm{H}_{2} \mathrm{O}_{2}$ generated by stimulated neutrophils or a cell-free enzymatic system (21). These data suggested that ferripyochelin might contribute to Pseudomonas-mediated tissue injury via the generation of cytotoxic hydroxyl radical.

Given: the evidence that Pseudomonas-derived secretory products could lead to generation of oxygen-centered free radicals; the tendency of this microorganism to invade vascular structures (22); the substantial evidence for the susceptibility of pulmonary endothelial cells to oxidant injury; and a role for such endothelial cell injury in the pathogenesis of several types of lung injury (23), we examined the effect of exposure of pulmonary artery endothelial cell monolayers to pyocyanin and/or ferripyochelin. By using spin trapping techniques, the nature of free radical species generated under such conditions was determined as well as the capacity of such exposures to cause cell injury. The implications of these results to the pathogenesis of tissue injury at sites of Pseudomonas infection are discussed.

\section{Methods}

\section{Purification of pyocyanin and pyochelin}

Apopyochelin was purified from broth culture of $P$. aeruginosa strain PA01 (ATCC 15692; American Type Culture Collection, Rockville, MD) by dichloromethane extraction and thin layer chromatography as previously described $(20,24)$. Ferripyochelin was generated by the addition of $\mathrm{FeCl}_{3}$ to a solution ( $100 \%$ ethanol) of apopyochelin at $\mathrm{pH}$ 5.0 to achieve $80 \%$ iron loading based on the known stoichiometry of iron/pyochelin of 1:2 (24). Fully loaded pyochelin was not employed to avoid any possibility of "free" iron in the experimental systems.

Pyocyanin was isolated from similar broth culture using a previously developed technique (25). Briefly, pyocyanin was extracted from culture supernatant of $P$. aeruginosa strain PA01 by consecutive chloroform extractions after which the chloroform layer was subjected to alternating extractions with acidified and neutralized water layers to allow separation of the red, acid form, and blue forms of pyocyanin. After five such conversions the pyocyanin was crystallized, washed with water, and dried under vacuum. Pyocyanin was solubilized in $\mathrm{H}_{2} \mathrm{O}$ before use.

\section{Endothelial cell culture}

Microcarrier beads. Confluent monolayers of porcine pulmonary artery endothelial cells were cultured on microcarrier beads (Cytodex 3 , Pharmacia, Inc., Piscataway, NJ) as previously described (26, 27). Multiple cell lines (passages 6-9) were employed for these studies. Cells were cultured for 2-3 d after confluence. Control experiments were performed simultaneously to eliminate any contribution of variation in cell line or passage number to the results. Before use, microcarrier beads were washed free of cell culture media (medium 199 containing $10 \%$ heat-inactivated fetal bovine serum, University of Iowa Cancer Center, Iowa City, IA ) by transferring the beads to a 50-ml conical tube (Sarstedt, Princeton, NJ) and allowing them to sediment ( $\sim 5 \mathrm{~min})$. Culture media was then removed by aspiration and replaced with $10 \mathrm{ml}$ of Hanks' balanced salt solution without phenol red (HBSS, University of Iowa Cancer Facility). Beads and HBSS were gently mixed and the beads allowed to resediment. The HBSS was then replaced with fresh HBSS and the process repeated three times. After the final wash the cells were resuspended in HBSS at $25 \%(\mathrm{vol} / \mathrm{vol})$ microcarrier beads which yields a final cell concentration of $0.5-1.0 \times 10^{7}$ cells $/ \mathrm{ml}$.
Microtiter plates. Porcine pulmonary artery endothelial cells were plated at a concentration of $5 \times 10^{4}$ cells per well in 24-well tissue culture plates (Costar, Cambridge, MA) in $0.5 \mathrm{ml}$ medium 199 with $10 \%$ serum, $2 \times$ basal medium amino acids, basal minimal essential vitamins, $2 \mathrm{mM}$ L-glutamine, $10 \mathrm{U} / \mathrm{ml}$ penicillin/streptomycin (Gibco Laboratories, Grand Island, NY). The plates were then placed in culture at $37^{\circ} \mathrm{C}, 5 \% \mathrm{CO}_{2}$ for $4-5 \mathrm{~d}$.

\section{Spin trapping}

Desired reaction mixtures $(0.5 \mathrm{ml})$ were assembled in $12 \times 75-\mathrm{mm}$ glass tubes and transferred to a quartz electron paramagnetic resonance (EPR) flat cell which was in turn placed into the cavity of the EPR spectrometer (model E104A, Varian Associates, Inc., Palo Alto, CA; or model ESP300, Bruker, Karlsruhe, FRG). Spin trapping systems consisted of $0.1 \mathrm{mM}$ diethylenetriaminepentaacetic acid (DTPA) and the following: $100 \mathrm{mM}$ 5,5-dimethyl-1-pyrroline- $N$-oxide (DMPO) with and without $170 \mathrm{mM}$ ethanol (27); $10 \mathrm{mM} \alpha$-phenyl- $N$ - $t$-butyl-nitrone $(\mathrm{PBN})$ plus $140 \mathrm{mM}$ dimethyl sulfoxide (DMSO) (28); or 10 $\mathrm{mM} \alpha$-(4-pyridyl-1-oxide)-N-t-butyl-nitrone (4-POBN) plus $170 \mathrm{mM}$ ethanol $(29,30)$. DMPO, DMSO, PBN, and 4-POBN were obtained from Sigma Chemical Co., St. Louis, MO and ethanol from Aaper Chemical Co., Shelbeysville, KY. Resulting EPR spectra were recorded sequentially at $25^{\circ} \mathrm{C}$. Routinely, for the Varian instrument spectrometer microwave power was $20 \mathrm{~mW}$, modulation frequency was $100 \mathrm{kHz}$ with a modulation amplitude of $1.0 \mathrm{G}$, response time was $1 \mathrm{~s}$, and the gain was $5 \times 10^{4}$. For experiments performed using the Bruker microwave power was $20 \mathrm{~mW}$, modulation frequency was $100 \mathrm{kHz}$ with a modulation amplitude of $0.892 \mathrm{G}$, time constant was 0.327 or $0.655 \mathrm{~s}$, and the gain was $5.0 \times 10^{5}$. In experiments containing endothelial cells the reaction mixtures contained $25 \%$ ( $\mathrm{vol} / \mathrm{vol}$ ) microcarrier beads in HBSS. In some cases experiments were performed under oxygen depleted conditions by bubbling the reaction mixture with $\mathrm{N}_{2}$ before initiation of the reaction. All buffers were routinely treated with chelating resin (Sigma Chemical Co.) to reduce the presence of adventitious iron, generally $\sim 1 \mu \mathrm{M}$ in most buffers. All EPR spectra shown are representative of experiments performed a minimum of three times.

\section{${ }^{51}$ Chromium Release}

Microtiter plate-adherent pulmonary artery endothelial cells were loaded with ${ }^{51} \mathrm{Cr}$, by incubation for $18 \mathrm{~h}\left(37^{\circ} \mathrm{C}, 5 \% \mathrm{CO}_{2}\right)$ in medium 199 (no additives) containing $20 \mu \mathrm{Ci} / \mathrm{ml}^{51} \mathrm{Cr}$ (sodium chromate, 2 $\mathrm{mCi} / \mathrm{ml}$; Amersham Corp., Arlington Heights, IL). Each well was then washed three times in ( $1 \mathrm{ml}$ per well). After the final wash, $1 \mathrm{ml}$ HBSS was added to each well and the plates were incubated for $30 \mathrm{~min}$ at $4^{\circ} \mathrm{C}$. Wells were then washed again with PBS after which $0.5 \mathrm{ml}$ medium 199 (no additives) was added to each well except for maximum release controls which contained medium 199 with $10 \%$ Triton X-100. Desired compounds were then added to each well (triplicate samples) and the cells allowed to incubate for $4 \mathrm{~h}\left(37^{\circ} \mathrm{C}, 5 \% \mathrm{CO}_{2}\right)$ after which the supernatants were removed and radioactivity determined by gamma counter. For experiments in which ferripyochelin, apopyochelin, or other iron chelates were used, cells were allowed to preincubate for 30 min in the presence of these compounds (or media alone) before the addition of other agents. At ethanol concentrations $\leq 0.4 \%$ ( $\mathrm{vol} / \mathrm{vol})$, at which all experiments were performed, there was no detectable increase in ${ }^{51} \mathrm{Cr}$ release above the spontaneous rate. Spontaneous release was measured as the amount of ${ }^{51} \mathrm{Cr}$ release over $4 \mathrm{~h}$ by cells incubated in medium 199 alone and was a mean of $21 \%$ of maximum release for all experiments performed.

1. Abbreviations used in this paper: DMPO, 5,5-dimethyl-1-pyrroline oxide; DMTU, dimethyl thiourea; DTPA, diethylenetriamine pentaacetic acid; EPR, electron paramagnetic resonance (spectrometry); PBN, $\alpha$-phenyl- $N$ - $t$-butyl-nitrone; 4-POBN, $\alpha$-(4-pyridyl-1-oxide)-Nt-butyl-nitrone. 
Results of each experiment are expressed as the mean specific ${ }^{51} \mathrm{Cr}$ release of triplicate samples where specific ${ }^{51} \mathrm{Cr}$ release is defined as:

(test well ${ }^{51} \mathrm{Cr} \mathrm{cpm}$ - spontaneous release ${ }^{51} \mathrm{Cr} \mathrm{cpm}$ )/

(maximum release ${ }^{51} \mathrm{Cr} \mathrm{cpm}-$ spontaneous release ${ }^{51} \mathrm{Cr} \mathrm{cpm}$ ).

\section{Other reagents}

Reduced $\beta$-nicotinamide adenine dinucleotide (NADH), catalase, human erythrocyte $\mathrm{CuZn}$ superoxide dismutase (SOD), and paraquat (methyl viologen) were obtained from Sigma. Dimethyl thiourea (DMTU) was purchased from Aldrich Chemical Co., Milwaukee, WI. Chromium oxalate which had been synthesized according to the method of Bailar and Jones (31) was kindly provided by Dr. Gerald Rosen, Dept. of Pharmacology, University of Maryland, Baltimore, MD.

\section{Statistical analysis of data}

A paired Student's $t$ test was used for all statistical analyses. Results were considered significant at $P<0.05$.

\section{Results}

Spin tapping of free radicals generated by the interaction of pyocyanin and $N A D H$. Before studying the nature of free radical species resulting from the interaction of pyocyanin and/or pyochelin with cells, we evaluated the chemistry of these two compounds under more controlled conditions. Consistent with earlier reports (32-34), addition of NADH to a solution of pyocyanin under anaerobic conditions resulted in the generation of the pyocyanin free radical (not shown). Other investigators have reported that in the presence of molecular oxygen $\left(\mathrm{O}_{2}\right)$, this pyocyanin radical will undergo oxidation to reform pyocyanin with the resultant generation of ${ }^{\circ} \mathrm{O}_{2}^{-}$(34-36), as well as $\mathrm{H}_{2} \mathrm{O}_{2}$ via the spontaneous dismutation of ${ }^{\circ} \mathrm{O}_{2}^{-}$. Superoxide and $\mathrm{H}_{2} \mathrm{O}_{2}$ can react with one another, albeit at a very slow rate (37), to generate the three electron reduction products of $\mathrm{O}_{2}$, hydroxyl radical. Therefore the possibility that additional free radical products other than ${ }^{\circ} \mathrm{O}_{2}^{-}$are produced as a consequence of the aerobic redox cycling of pyocyanin was examined using spin trapping. Pyocyanin $(40 \mu \mathrm{M})$ was added to a solution of NADH $(40 \mu \mathrm{M})$, DTPA $(0.1 \mathrm{mM})$ and the spin trap DMPO ( $100 \mathrm{mM})$ in $\mathrm{H}_{2} \mathrm{O}$ after which the EPR spectrum of this solution was continually monitored at $25^{\circ} \mathrm{C}$. The resulting EPR spectrum (Fig. $1 a$ ) was dominated by a nitroxide species whose hyperfine splitting constants $\left(A_{\mathrm{N}}=14.3, A_{\mathrm{H}}\right.$ $=11.8 \mathrm{G})$ are consistent with the superoxide-derived spin adduct of DMPO, DMPO/ $/{ }^{\circ} \mathrm{OOH}$. An additional nitroxide spe$\operatorname{cies}\left(A_{\mathrm{N}}=A_{\mathrm{H}}=14.9 \mathrm{G}\right)$ which is that of the hydroxyl radical
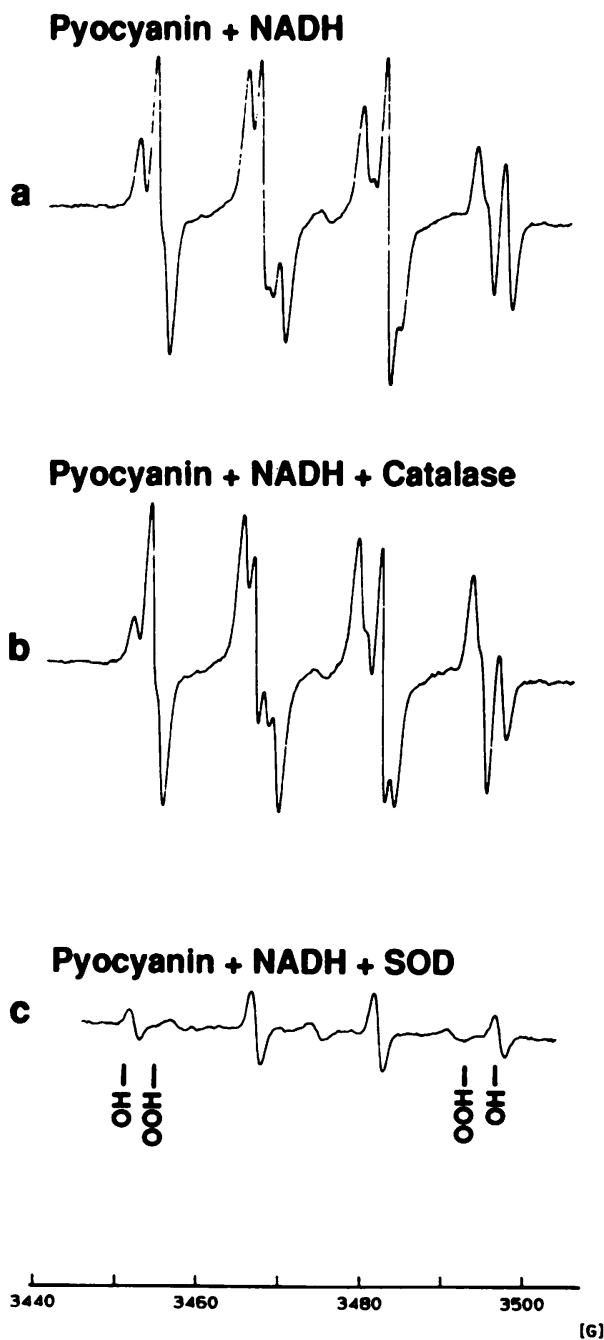
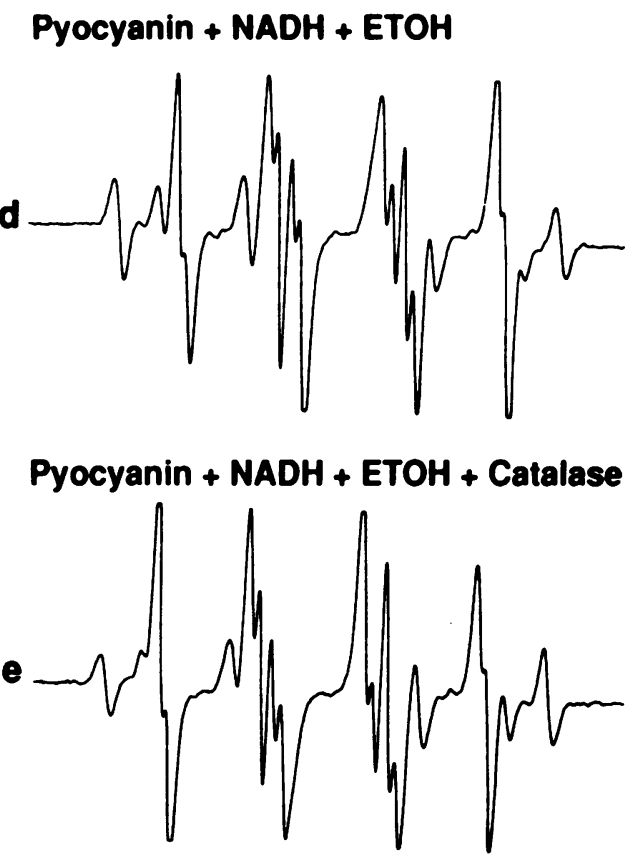

Pyocyanin + NADH + ETOH + SOD
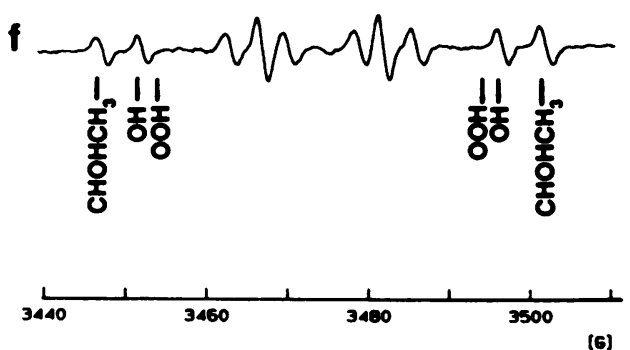

Figure 1. EPR spectra $a-c$ were obtained after the mixture of pyocyanin $(40 \mu \mathrm{M})$ and NADH $(40$ $\mu \mathrm{M})$ in the presence of $100 \mathrm{mM}$ DMPO and $0.1 \mathrm{mM}$ DTPA (tracing a) plus $500 \mathrm{U} / \mathrm{ml}$ catalase ( tracing b) or plus $30 \mathrm{U} / \mathrm{ml} \mathrm{SOD}$ (tracing $c$ ). EPR spectra $d-f$ were obtained under identical conditions to those corresponding to tracings $a-c$, respectively except that the reaction mixtures also contained $170 \mathrm{mM}$ ethanol. Spectra $a-c$ are those of the $\mathrm{DMPO} /{ }^{\circ} \mathrm{OOH}$ and DMPO/ ${ }^{\circ} \mathrm{OH}$ spin adducts which were inhibitable by the inclusion of SOD but not catalase consistent with the spin trapping of ${ }^{\circ} \mathrm{O}_{2}^{-}$. Spectra $d-f$ show no effect of ethanol on the results relative to spectra $a-c$ except for the appearance of a small amount of $\mathrm{DMPO} /{ }^{\circ} \mathrm{CHOHCH}{ }_{3}$ spin adduct which was inhibitable by SOD (tracing $f$ ) but not catalase (tracing $e)$. These results are consistent with only the spin trapping of ${ }^{\circ} \mathrm{O}_{2}^{-}$without any definitive evidence of spin trapping hydroxyl radical. The location of high and low field peaks corresponding to DMPO/ ${ }^{\circ} \mathrm{OOH}$, $\mathrm{DMPO} /{ }^{\circ} \mathrm{OH}$, and DMPO/

${ }^{\circ} \mathrm{CHOHCH}_{3}$ are designated $\mathrm{OOH}$, $\mathrm{OH}$, and $\mathrm{CHOHCH}_{3}$, respectively. 
spin adduct of DMPO, DMPO/ ${ }^{\circ} \mathrm{OH}$ (38) was also detected (Fig. 1 a). Previous work has shown that detection of DMPO/ ${ }^{\circ} \mathrm{OH}$ is not specific for the spin trapping of hydroxyl radical because it can also arise as a decomposition product of superoxide-induced DMPO/ ${ }^{\circ} \mathrm{OOH}$ (39).

To determine whether DMPO/ ${ }^{\circ} \mathrm{OH}$ generation resulted from the spin trapping of ${ }^{\circ} \mathrm{O}_{2}^{-}$or hydroxyl radical, experiments were repeated in the presence of $\operatorname{SOD}(30 \mathrm{U} / \mathrm{ml})$, catalase $(500 \mathrm{U} / \mathrm{ml})$, or ethanol $(170 \mathrm{mM})$. If $\mathrm{DMPO} /{ }^{\circ} \mathrm{OH}$ resulted from hydroxyl radical generation, all three of these compounds should inhibit its formation. In addition, in the case of ethanol which acts via its ability to scavenge hydroxyl radical, a new spin adduct derived from the spin trapping of the $\alpha$-hydroxyethyl radical product $\left({ }^{\circ} \mathrm{CHOHCH}{ }_{3}\right.$ ) of that reaction should be formed and should be inhibitable by catalase. In contrast, if $\mathrm{DMPO} /{ }^{\circ} \mathrm{OH}$ formation reflected spin trapping of ${ }^{\circ} \mathrm{O}_{2}^{-}$, only SOD would be expected to have a major effect. As shown in Fig. $1 c$, the presence of $\operatorname{SOD}(30 \mathrm{U} / \mathrm{ml})$ in the reaction mixture totally eliminated DMPO $/{ }^{\circ} \mathrm{OH}$ production. In contrast, catalase $(500 \mathrm{U} / \mathrm{ml})$ had no effect (Fig. $1 \mathrm{~b})$. Although inclusion of ethanol did result in the appearance of small DMPO/ ${ }^{\circ} \mathrm{CHOHCH}_{3}$ peaks $\left(A_{\mathrm{N}}=16.0, A_{\mathrm{H}}=22.8 \mathrm{G}\right.$, Fig. $\left.1 d\right)$, these were only inhibitable by SOD (Fig. $1 f$ ) but not catalase (Fig. 1 $e$ ), indicating that they likely resulted from spin trapping of hydroxyl radical which was also derived from the decomposition of DMPO/ ${ }^{\circ} \mathrm{OOH}$ as has been reported (39).

Recently, the sensitivity of DMPO spin trapping systems for hydroxyl radical has been brought into question because of the capacity of ${ }^{\circ} \mathrm{O}_{2}^{-}$to destroy the paramagnetic nature of hydroxyl radical-derived spin adducts of DMPO (40-42). Therefore, to confirm that the reaction of pyocyanin and NADH did not form hydroxyl radical, additional spin trapping experiments were performed in which the reaction was allowed to take place in the presence of either PBN and DMSO (28) or 4-POBN and ethanol (29). Neither of these two systems is capable of spin trapping ${ }^{\circ} \mathrm{O}_{2}^{-}$in a stable form. However, in the presence of hydroxyl radical both systems result in the formation of a spin adduct, $\mathrm{PBN} /{ }^{\circ} \mathrm{OCH}_{3}$ and $4-\mathrm{POBN} /{ }^{\circ} \mathrm{CHOHCH}$, respectively, which is not modified by ${ }^{\circ} \mathrm{O}_{2}^{-}(28,29)$. Recent data suggests that the 4-POBN/ethanol system is 10 times more sensitive for hydroxyl radical than that of DMPO (29, $30)$. Nevertheless, when pyocyanin and NADH were mixed in the presence of 4-POBN/ethanol (Fig. $2 a$ ) or PBN/DMSO (not shown) no EPR signal above background was detectable confirming the lack of hydroxyl radical formation by this reaction.

Ferripyochelin will catalyze formation of hydroxyl radical from the interaction of pyocyanin and $N A D H$. We previously showed that iron bound to the Pseudomonas siderophore pyochelin can catalyze hydroxyl radical generation from ${ }^{\circ} \mathrm{O}_{2}^{-} /$ $\mathrm{H}_{2} \mathrm{O}_{2}$ produced by the reaction of xanthine oxidase and hypoxanthine or by PMA-stimulated neutrophils (21). Given the considerable likelihood that pyocyanin and ferripyochelin would coexist in vivo, evidence for formation of hydroxyl radical was sought during the reaction of pyocyanin and NADH in the presence of ferripyochelin using the 4-POBN/ ethanol spin trapping system. The hydroxyl radical-derived spin adduct, 4POBN $/{ }^{\circ} \mathrm{CHOHCH}{ }_{3}\left(A_{\mathrm{N}}=15.8, A_{\mathrm{H}}=2.4 \mathrm{G}\right)$ was detectable with the combination of pyocyanin and ferripyochelin (Fig. 2 b) but not with either alone (Fig. 2, $a$ and $c$ ). 4-POBN/
Pyocyanin + NADH
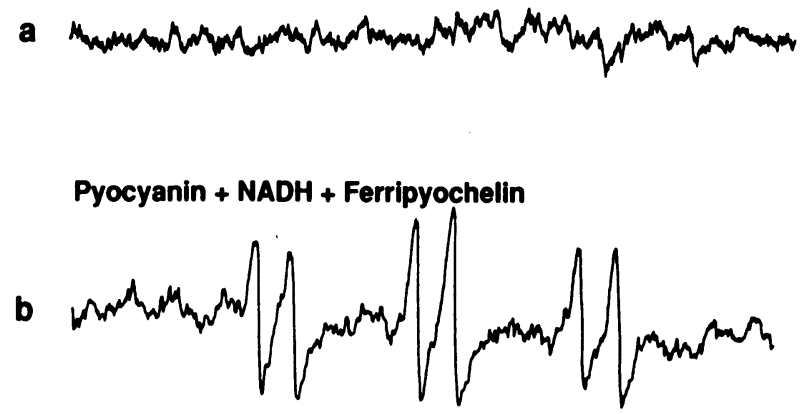

NADH + Ferripyochelin

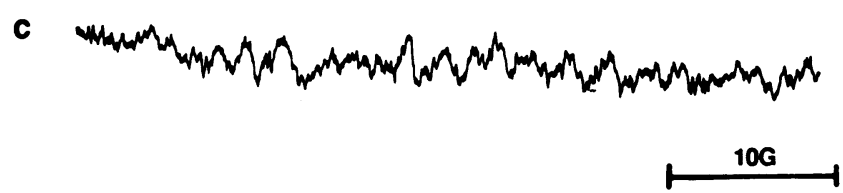

Figure 2. EPR spectra obtained by using the 4-POBN/ethanol spintrapping system and resulting from the reaction of pyocyanin (40 $\mu \mathrm{M})$ and NADH $(40 \mu \mathrm{M})$ in the presence (tracing $b)$ and absence (tracing $a$ ) of $10 \mu \mathrm{M}$ ferripyochelin. Also shown is the result obtained with NADH and ferripyochelin in the absence of pyocyanin (tracing $c)$. The species detected with the mixture of NADH, pyocyanin, and ferripyochelin is that of 4-POBN $/{ }^{\circ} \mathrm{CHOHCH}_{3}$ indicating hydroxyl radical production.

${ }^{\circ} \mathrm{CHOHCH}_{3}$ was inhibited by catalase and SOD (not shown) consistent with hydroxyl radical formation via the HaberWeiss (superoxide-driven Fenton) reaction (43).

Detection of free radicals formed after the exposure of endothelial cells to pyocyanin. The above and earlier data (34-36) suggested that redox cycling of pyocyanin could serve as a continuous source of ${ }^{\circ} \mathrm{O}_{2}^{-}$( and therefore $\mathrm{H}_{2} \mathrm{O}_{2}$ ) in biological systems. Endothelial cells are susceptible to $\mathrm{H}_{2} \mathrm{O}_{2}$-mediated injury (44-49). Hydroxyl radical resulting from the interaction of exogenous $\mathrm{H}_{2} \mathrm{O}_{2}$ and endothelial cell associated-iron has been suggested to be responsible for this cell injury (49). Consistent with these data, we have recently spin-trapped hydroxyl radical after exposure of endothelial cells to $\mathrm{H}_{2} \mathrm{O}_{2}(27)$. In that endothelial cells may well be exposed to pyocyanin during the course of localized or bacteremic infections with $P$. aeruginosa, the nature of free radical species generated by the exposure of endothelial cell monolayers to pyocyanin was examined. This was done using a previously developed spin trapping technique which utilizes microcarrier bead-adherent porcine pulmonary artery endothelial cells (27). When such a "suspension of adherent endothelial cells" was exposed to $40 \mu \mathrm{M}$ pyocyanin in the presence of DMPO, an EPR spectrum consistent with DMPO $/{ }^{\circ} \mathrm{OH}$ was detected (Fig. $3 a$ ). Generation of this spin adduct was inhibited by SOD (Fig. $3 b$ ) but not catalase (Fig. 3 $c$ ) or ethanol (Fig. $3 d$ ). These results are consistent with the spin trapping of ${ }^{\circ} \mathrm{O}_{2}^{-}$as had been observed with the reaction of pyocyanin and NADH (Fig. $1 a$ ). No evidence of hydroxyl radical was apparent in these experiments or when they were 

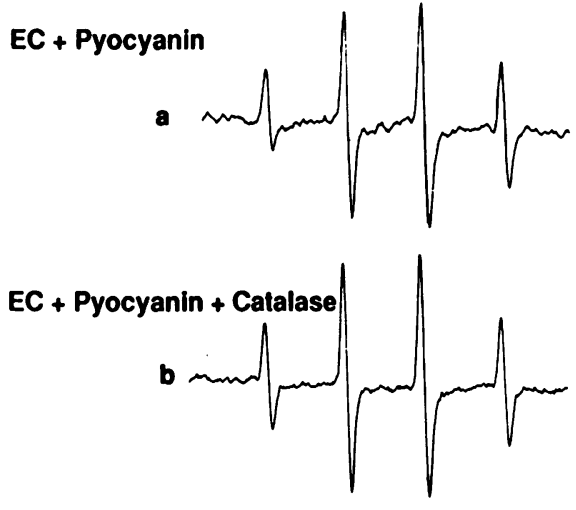

$E C+$ Pyocyanin + SOD

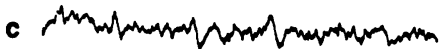

EC + Pyocyanin + ETOH (1/2 Gain)

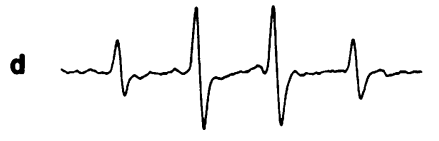

EC + Pyocyanin (4-POBN/ETOH)

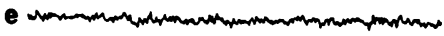

Figure 3. EPR spectra obtained after the addition of $40 \mu \mathrm{M}$ pyocyanin to microcarrier bead adherent porcine pulmonary artery endothelial cells $(25 \% \mathrm{vol} / \mathrm{vol})$ in the presence of DMPO (tracing $a)$ as well as $500 \mathrm{U} / \mathrm{ml}$ catalase (tracing $b$ ), or $30 \mathrm{U} / \mathrm{ml} \mathrm{SOD} \mathrm{(tracing} c$ ), or 170 $\mathrm{mM}$ ethanol (tracing $d$ ). Note that tracing $d$ was obtained at half the gain of the other three scans. Tracing a reveals a single nitroxide species whose splitting constants correspond to DMPO/ $/{ }^{\circ} \mathrm{OH}$. As shown in tracings $b-d$ its detection was inhibitable by SOD but not catalase or ethanol consistent with spin trapping of ${ }^{\circ} \mathrm{O}_{2}^{-}$. Also shown is the result obtained under conditions identical to those of tracing a except that the combination of $10 \mathrm{mM} 4-\mathrm{POBN}$ and $170 \mathrm{mM}$ ethanol was substituted for DMPO. The resulting EPR spectrum reveals no species above background further confirming the absence of detectable hydroxyl radical production.

repeated using the more sensitive 4-POBN/ethanol spin trapping system (Fig. $3 e$ ).

In our earlier study (27), hydroxyl radical generated by endothelial cell exposure to $\mathrm{H}_{2} \mathrm{O}_{2}$ appeared to occur at an intracellular site as indicated by the inability of the "EPR line-broadening agent" chromium oxalate, which is excluded from intracellular sites, to eliminate the EPR spectrum of the resulting spin adduct. Therefore, the presumed catalyst for hydroxyl radical generation was likely an intracellular iron chelate. In the present set of experiments, chromium oxalate almost totally eliminated the DMPO/ ${ }^{\circ} \mathrm{OH}$ spectrum resulting from the spin trapping of ${ }^{\circ} \mathrm{O}_{2}^{-}$generated by endothelial cells exposed to pyocyanin (Fig. 4), indicating it arose extracellularly or in close proximity to the cell membrane. As previously noted with paraquat (27), the site of ${ }^{\circ} \mathrm{O}_{2}^{-} / \mathrm{H}_{2} \mathrm{O}_{2}$ generation induced by pyocyanin is therefore quite distant from potential intracellular catalytic iron chelates.
Generation of hydroxyl radical during the exposure of endothelial cells to pyocyanin and ferripyochelin. The Pseudomonas siderophore pyochelin is hydrophobic (20) suggesting that it will readily associate with cellular membranes. Given the above data that exposure of endothelial cells to pyocyanin results in the continuous formation of ${ }^{\circ} \mathrm{O}_{2}^{-} / \mathrm{H}_{2} \mathrm{O}_{2}$ near the cell surface the possibility that treatment of endothelial cells with pyocyanin and ferripyochelin would result in the generation of hydroxyl radical was examined. Microcarrier bead-adherent porcine pulmonary artery endothelial cells were incubated with pyocyanin $(40 \mu \mathrm{M})$ in the presence of ferripyochelin (10 $\mu \mathrm{M}$ ) and hydroxyl radical production assessed by spin trapping with 4-POBN/ethanol. As shown in Fig. 5, the 4-POBN/ ${ }^{\circ} \mathrm{CHOHCH}_{3}$ spin adduct was readily detectable after such treatment. Formation of this spin adduct was inhibited by catalase and to a lesser extent SOD (Fig. 5), as would be expected if it arose from spin trapping of hydroxyl radical generated through the Haber-Weiss reaction. Substitution of apopyochelin also eliminated spin adduct generation ( Fig. 5), demonstrating the necessity for iron in the system and providing further evidence for involvement of the Haber-Weiss reaction. Addition of chromium oxalate to a suspension of endothelial cells treated with pyocyanin and ferripyochelin almost total eliminated the 4-POBN $/{ }^{\circ} \mathrm{CHOHCH}_{3}$ spectrum (Fig. 6) consistent with spin trapping of hydroxyl radical generated extracellularly or in close proximity to the cell membrane. Unfortunately, DMPO spin trapping could not be employed to confirm our

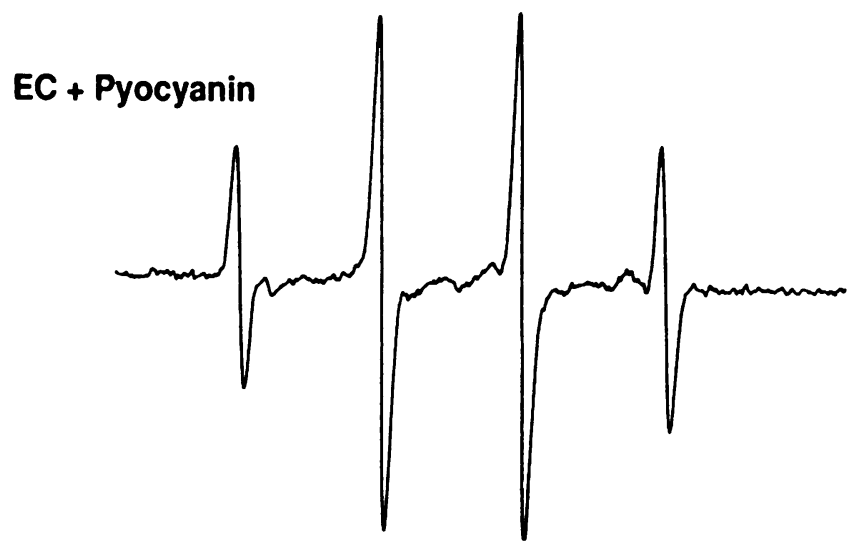

\section{EC + Pyocyanin + CrOx}

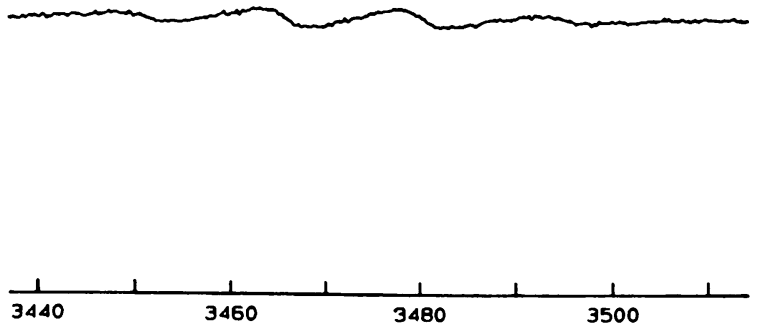

[G]

Figure 4. EPR spectra resulting from the exposure of endothelial cells to $40 \mu \mathrm{M}$ pyocyanin in the presence of $100 \mathrm{mM}$ DMPO and $0.1 \mathrm{mM}$ DTPA in the absence (top scan) and presence (bottom scan) of the EPR line-broadening agent chromium oxalate $(10 \mathrm{mM})$. 

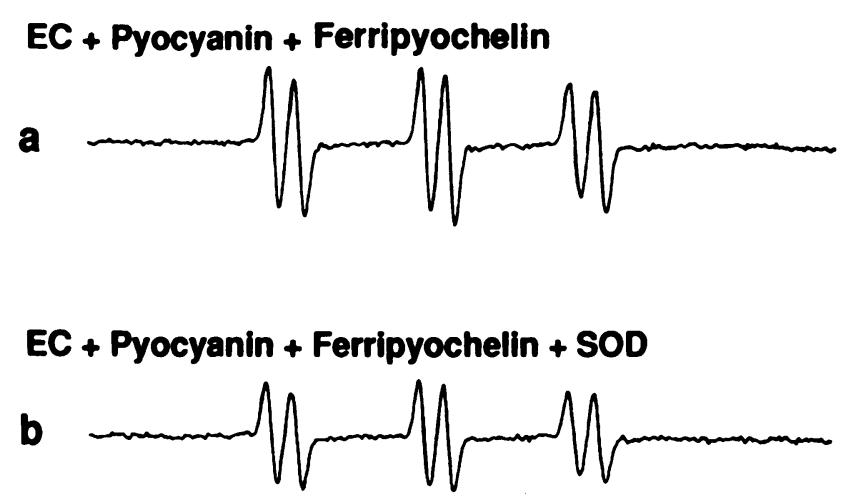

\section{EC + Pyocyanin + Ferripyochelin + Catalase}

C

\section{EC + Pyocyanin + Apopyochelin}

d

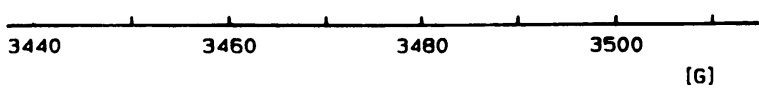

Figure 5. EPR spectra obtained using the 4-POBN/ethanol spintrapping system in which microcarrier bead-adherent endothelial cells were exposed to $40 \mu \mathrm{M}$ pyocyanin and $10 \mu \mathrm{M}$ ferripyochelin in the presence of $0.1 \mathrm{mM}$ DTPA alone (tracing $a$ ) plus $10 \mathrm{U} / \mathrm{ml}$ SOD (tracing $b$ ) or plus $500 \mathrm{U} / \mathrm{ml}$ catalase (tracing $c$ ). Results reveal that endothelial cell exposure to the combination of ferripyochelin and pyocyanin results in the generation of the $4-\mathrm{POBN} /{ }^{\circ} \mathrm{CHOHCH}_{3}$ spin adduct, which is inhibited slightly by the presence of SOD and to a greater extent by catalase. Tracing $d$ was obtained under the same conditions as tracing $a$ except that apopyochelin was substituted for ferripyochelin. Tracing $d$ therefore demonstrates that the generation of hydroxyl radical is dependent on the presence of iron.

results. Consistent with our earlier experience (21), in the buffer systems necessary to maintain endothelial cell viability, the simultaneous presence of ferripyochelin and DMPO resulted in the generation of confounding nitroxide species.

Endothelial cell damage by pyocyanin and ferripyochelin. Given the susceptibility of endothelial cells to oxidant-mediated injury, the effect of pyocyanin and ferripyochelin exposure on endothelial cell viability was assessed. As quantitated by the release of ${ }^{51} \mathrm{Cr}$ from prelabeled adherent endothelial cells, $40 \mu \mathrm{M}$ pyocyanin resulted in only slight, although statistically significant, cell injury (Table I). Increasing the concentration of pyocyanin 10-fold failed to increase the magnitude of endothelial cell injury (data not shown ). Similarly, when endothelial cells were exposed to ferripyochelin alone, a small but significant increase in ${ }^{51} \mathrm{Cr}$ release was detectable $(6.8 \pm 1.8 \%$

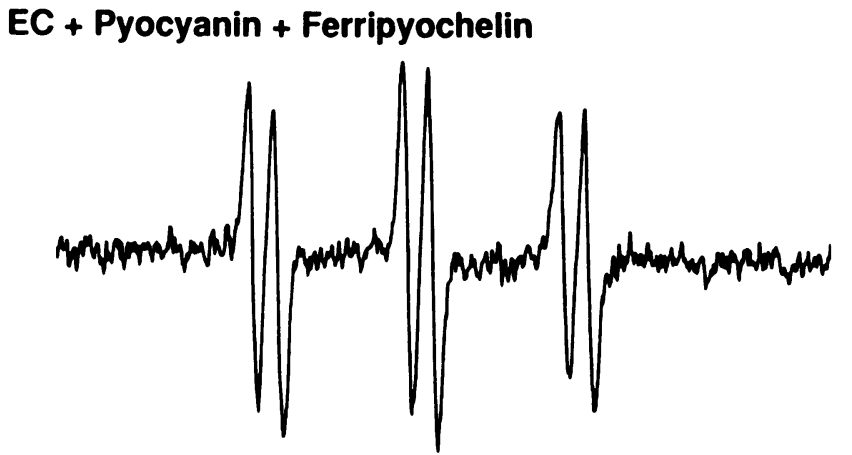

EC + Pyocyanin + Ferripyochelin + CrOx
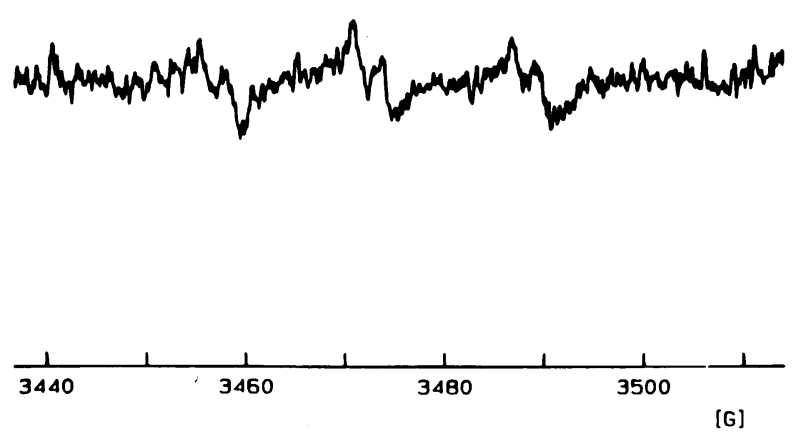

Figure 6. EPR spectra resulting from the exposure of endothelial cells to $40 \mu \mathrm{M}$ pyocyanin and $10 \mu \mathrm{M}$ ferripyochelin in the presence of 10 $\mathrm{mM}$ 4-POBN, $170 \mathrm{mM}$ ethanol, and $0.1 \mathrm{mM}$ DTPA in the absence (top scan) and presence (bottom scan) of the EPR line-broadening agent chromium oxalate $(10 \mathrm{mM})$.

mean $\pm \mathrm{SEM}$ specific ${ }^{51} \mathrm{Cr}$ release, $\left.n=12, P \leq 0.05\right)$. However, addition of pyocyanin $(40 \mu \mathrm{M})$ to an endothelial cell monolayer which had been preincubated in the presence of $10 \mu \mathrm{M}$ ferripyochelin for $30 \mathrm{~min}$ resulted in a much greater magnitude of cell injury than observed with either agent alone: $55 \%$ specific ${ }^{51} \mathrm{Cr}$ release ( Table I). No increase in cell injury above that induced by pyocyanin alone was detected when apopyochelin

Table I. Specific ${ }^{5 I}$ Cr Release

\begin{tabular}{lccccc}
\hline & Alone & FePCH & ApoPCH & FeNTA & FeEDTA \\
\hline Pyocyanin & $6.5 \pm 2.0^{*}$ & $54.7 \pm 5.2^{\ddagger}$ & $13.5 \pm 3.4$ & $4.1 \pm 2.3$ & $3.5 \pm 2.4$ \\
Paraquat & $8.5 \pm 4.8$ & $11.2 \pm 3.7$ & ND & ND & ND \\
\hline
\end{tabular}

Shown is the mean $\pm \mathrm{SEM}$ of specific ${ }^{51} \mathrm{Cr}$ release as calculated per Methods, obtained after 4-h incubation of porcine pulmonary artery endothelial cell monolayers in the presence of $40 \mu \mathrm{M}$ pyocyanin alone and under conditions in which the cells were preincubated for 30 min in the presence of $10 \mu \mathrm{M}$ ferripyochelin, apopyochelin, ferric nitrilotriacetic acid (FeNTA), or ferric ethylenediaminetetraacetic acid (FeEDTA) before the addition of pyocyanin. In each of the latter cases the system also contained $0.4 \%$ ( $\mathrm{vol} / \mathrm{vol}$ ) ethanol. Also shown are results obtained when $10 \mathrm{mM}$ paraquat was substituted for pyocyanin. Each experiment was performed a minimum of three times (range 3-11). ND, not done. ${ }^{*}$ Statistically significant, $P \leq 0.05$.

${ }^{\ddagger}$ Statistically significant, $P \leq 10^{-6}$. 
was used in place of ferripyochelin (Table I), indicating that ferripyochelin augmentation of pyocyanin-mediated injury was dependent on the presence of iron and not related to the ethanol vehicle in which the pyochelin was prepared. ${ }^{51} \mathrm{Cr}$ release above background was not detected at ferripyochelin concentrations below $10 \mu \mathrm{M}$, even when the pyocyanin concentration was increased to $400 \mu \mathrm{M}$ (data not shown). The effect of increasing the concentration of ferripyochelin above $10 \mu \mathrm{M}$ could not be evaluated because such experiments required ethanol concentrations (the pyochelin vehicle) which produced variable cytotoxicity by themselves.

Catalase and the $\mathrm{H}_{2} \mathrm{O}_{2} /{ }^{\circ} \mathrm{OH}$ scavenger DMTU protected endothelial cells from pyocyanin/ferripyochelin-mediated injury. The presence of $500 \mathrm{U} / \mathrm{ml}$ catalase or $50 \mathrm{mM}$ DMTU decreased pyocyanin/ferripyochelin-induced ${ }^{51} \mathrm{Cr}$ release by $63.2 \pm 9.2 \%$ and $57.9 \pm 11.4 \%($ mean \pm SEM, $n=5)$, respectively. DMSO ( $140 \mathrm{mM})$ and SOD $(300 \mathrm{U} / \mathrm{ml})$, however, had little effect on pyocyanin/ferripyochelin-induced injury. ${ }^{51} \mathrm{Cr}$ release resulting from pyocyanin/ferripyochelin exposure decreased only $10.5 \pm 4.2 \%$ and $5.9 \pm 3.1 \%$ (mean \pm SEM, $n=5$ ) in the presence of DMSO and SOD, respectively.

In order to ascertain whether ferripyochelin was unique among iron chelates in its ability to increase injury in pyocyanin-exposed endothelial cells, experiments were repeated in which two other iron-complexes known to be active as hydroxyl radical catalysts replaced ferripyochelin. Substitution of equimolar concentrations $(10 \mu \mathrm{M})$ of ferric nitrilotriacetic acid or ferric EDTA for ferripyochelin did not increase cell injury above that observed with pyocyanin-treated endothelial cell monolayers even when ethanol was included in the system ( Table I). Similarly, to assess the uniqueness of the pyocyanin role in the above process, the redox active xenobiotic paraquat (methyl viologen), which induces ${ }^{\circ} \mathrm{O}_{2}^{-}$formation in porcine pulmonary artery endothelial cells (27), was substituted for pyocyanin in the above experiments. At a $10 \mathrm{mM}$ concentration of paraquat, which, as previous spin-trapping data (27) indicates, induces magnitudes of ${ }^{\circ} \mathrm{O}_{2}^{-}$production in porcine endothelial cells similar to that of $40 \mu \mathrm{M}$ pyocyanin, no significant specific ${ }^{51} \mathrm{Cr}$ release was observed in the absence or presence of $10 \mu \mathrm{M}$ ferripyochelin (Table I). Thus, within the limitations of the experimental system employed only the combination of pyocyanin and ferripyochelin appeared to induced a large amount of endothelial cell injury.

\section{Discussion}

A common sequela of septicemia as well as localized infection with $P$. aeruginosa is microvascular injury and thrombosis (22). The susceptibility of endothelial cells to oxidant-mediated injury is well recognized and has been implicated in the pathogenesis of a number of disease states (23). The $P$. aeruginosa secretory product pyocyanin can undergo redox cycling with resultant formation of ${ }^{\circ} \mathrm{O}_{2}^{-} / \mathrm{H}_{2} \mathrm{O}_{2}$ (34-36). In addition, we have recently demonstrated that iron bound to the $P$. aeruginosa siderophore pyochelin is capable of catalyzing the formation of hydroxyl radical from ${ }^{\circ} \mathrm{O}_{2}^{-} / \mathrm{H}_{2} \mathrm{O}_{2}$ (21). Therefore, experiments were performed to assess the potential role of pyocyanin and/or ferripyochelin-mediated oxidant production in Pseudomonas-associated endothelial cell injury.

Consistent with previous work with pyocyanin $(5,25,34$,
$50,51)$ and other redox active compounds $(27,52,53),{ }^{\circ} \mathrm{O}_{2}^{-}$ but not hydroxyl radical was spin trapped during the reaction of pyocyanin with NADH or after the exposure of pulmonary artery endothelial cell monolayers to pyocyanin. In contrast, a small amount of hydroxyl radical has been reportedly spin trapped with addition of pyocyanin to $E$. coli, particularly a catalase-deficient strain (50). These data suggest that the reduction of pyocyanin by NADH or cellular enzyme systems does not generate hydroxyl radical within the limits of sensitivity of spin trapping. The potential for pyocyanin reduction to result in the formation of hydroxyl radical is likely dependent on the simultaneous presence of a transition metal catalyst and the relative antioxidant defenses of the cell. The location of free radical production is likely an important factor in determining the relative toxicity of such oxidants in biologic systems. Our data suggest that, like paraquat (27), most of the ${ }^{\circ} \mathrm{O}_{2}^{-}$spin trapped during endothelial cell exposure to pyocyanin is generated close to the cell surface.

Iron complexes capable of catalyzing the Haber-Weiss reaction are quite limited in vivo (16). Sites of $P$. aeruginosa infection would likely contain both pyocyanin and ferripyochelin $(8,54,55)$. Consistent with our earlier work $(21)$, the presence of ferripyochelin during the production of ${ }^{\circ} \mathrm{O}_{2}^{-} / \mathrm{H}_{2} \mathrm{O}_{2}$ by pyocyanin and NADH resulted in hydroxyl radical generation. Of greater biologic relevance, addition of pyocyanin to endothelial cell monolayers preincubated with ferripyochelin also resulted in hydroxyl radical formation. The effects of SOD, catalase and chromium oxalate suggested this was the result of the HaberWeiss reaction occurring in close proximity to the cell surface.

As assessed by the release of ${ }^{51} \mathrm{Cr}$ from prelabeled cells, pyocyanin and ferripyochelin alone caused minimal endothelial cell damage. Our detection of some pyocyanin-mediated injury differs from a previous report (51) which found no such damage as assessed by lactose dehydrogenase release. However, concerns have recently been expressed that pyocyanin may interfere with quantitation of lactose dehydrogenase activity (56). In addition, both lactose dehydrogenase and ${ }^{51} \mathrm{Cr}$ release are rather insensitive means of assessing endothelial cell injury. Pyocyanin has been reported to have deleterious effects on both respiratory epithelial cells $(8-10,57,58)$ and cells involved in host defense (59-66). Of additional note, exposure to $\mathrm{H}_{2} \mathrm{O}_{2}$ or the induction of oxidant production via xenobiotics other than pyocyanin (e.g., menadione) have been shown to have effects on endothelial and/or epithelial cells which could augment the potential for inflammatory tissue injury (67-77). The possibility that pyocyanin-induced ${ }^{\circ} \mathrm{O}_{2}^{-} / \mathrm{H}_{2} \mathrm{O}_{2}$ could lead to similar changes is likely worth investigating.

The combination of the same concentrations of pyocyanin and ferripyochelin which by themselves caused only minimal cytotoxicity resulted in nearly $55 \%$ cell lysis. The process is iron-dependent implying involvement of iron-catalyzed hydroxyl radical formation. Furthermore, both catalase and DMTU, a low molecular weight membrane permeable compound which prevents hydroxyl radical formation by scavenging $\mathrm{H}_{2} \mathrm{O}_{2}(78)$, were protective. However, SOD and DMSO offered no protection. This is consistent with the minimal decrease in hydroxyl radical production by pyocyanin/ferripyochelin treated endothelial cells in the presence of SOD (Fig. 5). SOD may not adequately reach the site of ${ }^{\circ} \mathrm{O}_{2}^{-}$interaction with ferripyochelin, presumably the cell membrane, to adequately 
prevent redox cycling of the catalytic iron. Similarly, DMSO may not be able to achieve concentrations within the cell membrane sufficient to scavenge hydroxyl radical before it interacts with oxidizable membrane components. As additional evidence that this process likely involves hydroxyl radical-mediated toxicity, we have recently found that ferripyochelin markedly enhances the ability of products of the reaction of xanthine and xanthine oxidase $\left({ }^{\circ} \mathrm{O}_{2}^{-} / \mathrm{H}_{2} \mathrm{O}_{2}\right)$ to damage pulmonary artery endothelial cells (manuscript in preparation).

Substitution of other catalytic iron chelates for ferripyochelin or another redox active xenobiotic (paraquat) for pyocyanin did not cause the magnitude of endothelial cell injury observed with the pyocyanin/ferripyochelin combination. These data suggest a unique interaction between these two compounds which apparently results in the generation of a highly toxic free radical species at a site which is capable of causing considerable cell injury.

The concentration of pyocyanin and pyochelin to which endothelial cells may be exposed in vivo is unknown. However, the concentration of pyocyanin employed in our study is similar to that detected in sputum sol of $P$. aeruginosa-infected patients (8). Quantitation of pyochelin present in vivo at sites of $P$. aeruginosa infection has not been reported. However, the concentration of pyochelin utilized in these studies was below that which routinely accumulates in in vitro broth culture of the organism (20). Given the lipophilic nature of pyochelin the concentration of the compound achievable at an endothelial cell membrane may be higher than this, particularly under conditions in which the organism is adherent to the cell surface. We have also recently found that another pseudomonas secretory product, pseudomonas elastase, is capable of cleaving ferritransferrin to yield novel iron chelates which are also able to catalyze the production of hydroxyl radical from ${ }^{\circ} \mathrm{O}_{2}^{-} / \mathrm{H}_{2} \mathrm{O}_{2}$ (79). Such iron chelates, whose generation is enhanced by the simultaneous presence of human neutrophil elastase (79), could also potentially interact with pyocyanin-derived ${ }^{\circ} \mathrm{O}_{2}^{-}$/ $\mathrm{H}_{2} \mathrm{O}_{2}$ in a fashion analogous to ferripyochelin to enhance the potential for the formation of hydroxyl radical at sites of $P$. aeruginosa infection.

In summary, we have obtained in vitro evidence that two well-characterized secretory products of $P$. aeruginosa, pyocyanin and pyochelin, which have previously been suggested as virulence factors in vivo $(2,22)$, can act in a synergistic fashion to damage pulmonary artery endothelial cells. The mechanism appears to involve the endothelial cell-mediated redox cycling of pyocyanin leading to ${ }^{\circ} \mathrm{O}_{2}^{-} / \mathrm{H}_{2} \mathrm{O}_{2}$ production which is then converted to the more cytotoxic hydroxyl radical via the catalytic activity of ferripyochelin. Clearly the tissue destruction so characteristic of $P$. aeruginosa infections does not likely result exclusively from oxidant-mediated injury. A host of other $P$. aeruginosa virulence factors have been described (4). Nevertheless, the results of studies carried out thus far suggest that the role of oxygen-centered free radicals in the pathogenesis of $P$. aeruginosa and other bacterial infections is an area worthy of additional study.

\section{Acknowledgments}

We thank Dr. Garry Buettner of the University of Iowa ESR facility for his assistance with the detection of the pyocyanin free radical, Kathy
Lindsley for her cell culture work, and Naomi Erickson for her help with preparation of the manuscript.

This work was supported in part by awards from the VA Research Service, Public Health Service grants HL-44275, AI-28412, HL-33540, HL-42385, and AI-13120, The Cystic Fibrosis Foundation, and a grant-in-aid from the American Heart Association. This work was performed during the tenure of Drs. Britigan and Shasby as a Research Associate and a Clinical Investigator, respectively, of the VA Research Service.

\section{References}

1. Pennington, J. P. 1990. Nosocomial respiratory infection. In Principles and Practice of Infectious Diseases. G. L. Mandell, R. G. Douglas, Jr., and J. E. Bennett, editors. Churchill Livingstone, New York. 2199-2205.

2. Fick, R. B., Jr., and J. S. Hata. 1989. Pathogenetic mechanisms in lung disease caused by Pseudomonas aeruginosa. Chest. 95:206S-213S.

3. Stern, R. C., R. E. Wood, T. F. Boat, L. W. Matthews, A. S. Tucker, and C. F. Doershuk. 1978. Treatment and prognosis of massive hemoptysis in cystic fibrosis. Am. Rev. Respir. Dis. 117:825-828.

4. Fick, R. B., Jr. 1989. Pathogenesis of the Pseudomonas lung lesion in cystic fibrosis. Chest. 96:158-164.

5. Hassan, H. M., and I. Fridovich. 1980. Mechanism of the antibiotic action of pyocyanine. J. Bacteriol. 141:156-163.

6. Armstrong, A. V., D. E. S. Stewart-Tull, and J. S. Roberts. 1971. Characterization of the Pseudomonas aeruginosa factor that inhibits mouse-liver mitochondrial respiration. J. Med. Microbiol. 4:249-262.

7. Friedheim, E. A. H. 1934. XXV. The effect of pyocyanine on the respiration of some normal tissues and tumours. Biochem. J. 28:173-179.

8. Wilson, R., D. A. Sykes, D. Watson, A. Rutman, G. W. Taylor, and P. J. Cole. 1988. Measurement of Pseudomonas aeruginosa phenazine pigments in sputum and assessment of their contribution to sputum sol toxicity for respiratory epithelium. Infect. Immun. 2515:2517.

9. Munro, N. C., A. Barker, A. Rutman, G. Taylor, D. Watson, W. J. McDonald-Gibson, R. Towart, W. A. Taylor, R. Wilson, and P. J. Cole. 1989. Effect of pyocyanin and 1-hydroxyphenazine on in vivo tracheal mucus velocity. J. Appl. Physiol. 67:316-323.

10. Wilson, R., T. Pitt, G. Taylor, D. Watson, J. MacDermot, D. Sykes, D. Roberts, and P. Cole. 1987. Pyocyanin and 1-hydroxyphenazine produced by Pseudomonas aeruginosa inhibit the beating of human respiratory cilia in vitro. J. Clin. Invest. 79:221-229.

11. Cohen, M. S., B. E. Britigan, D. J. Hassett, and G. M. Rosen. 1988. Do human neutrophils form hydroxyl radical? Evaluation of an unresolved controversy. Free Radical Biol. Med. 5:81-88.

12. Weiss, S. J. 1986. Oxygen, ischemia and inflammation. Acta Physiol. Scand. (Suppl.)548:9-37.

13. Winterbourn, C. C. 1983. Lactoferrin-catalyzed hydroxyl radical production: additional requirements for a chelating agent. Biochem. J. 210:15-19.

14. Baldwin, D. A., E. R. Jenny, and P. Aisen. 1984. The effect of human serum transferrin and milk lactoferrin on hydroxyl radical formation from superoxide and hydrogen peroxide. J. Biol. Chem. 259:13391-13394.

15. Buettner, G. R. 1987. The reaction of superoxide, formate radical, and hydrated electron with transferrin and its model compound, Fe(III)-eyhylenediamine- $N, N^{\prime}$-bis [2-(2-hydroxyphenyl)acetic acid] as studied by pulse radiolysis. J. Biol. Chem. 262:11995-11998.

16. Halliwell, B., and J. M. C. Gutteridge. 1986. Oxygen radicals and iron in relation to biology and medicine: some problems and concepts. Arch. Biochem. Biophys. 246:501-514.

17. O'Connell, M., B. Halliwell, C. P. Moorhouse, O. I. Aruoma, H. Baum, and T. J. Peters. 1986. Formation of hydroxyl radicals in the presence of ferritin and haemosiderin: is haemosiderin formation a biological protective mechanism? Biochem. J. 234:727-731.

18. Ozaki, M., T. Kawabata, and M. Awai. 1988. Iron release from haemosiderin and production of iron-catalyzed hydroxyl radicals in vitro. Biochem. J. 250:589-595.

19. Cox, C. D., and P. Adams. 1985. Siderophore activity of pyoverdin for Pseudomonas aeruginosa. Infect. Immun. 48:130-138.

20. Cox, C. D., K. L. Rinehart, Jr., M. L. Moore, and C. J. Cook, Jr. 1981. Pyochelin: novel structure of an iron-chelating growth promoter for Pseudomonas aeruginosa. Proc. Natl. Acad. Sci. USA. 78:4256-4260.

21. Coffman, T. J., C. D. Cox, B. L. Edeker, and B. E. Britigan. 1990. Possible role of bacterial siderophores in inflammation: iron bound to the Pseudomonas 
siderophore pyochelin can function as a hydroxyl radical catalyst. J. Clin. Invest. 86:1030-1037.

22. Bodey, G. P., R. Bolivar, V. Fainstein, and L. Jadeja. 1983. Infections caused by Pseudomonas aeruginosa. Rev. Infect. Dis. 5:279-313.

23. Heffner, J. E., and J. E. Repine. 1989. Pulmonary strategies of antioxidant defense. Am. Rev. Respir. Dis. 140:531-554.

24. Cox, C. D., and R. Graham. 1979. Isolation of an iron-binding compound from Pseudomonas aeruginosa. J. Bacteriol. 137:357-364.

25. Cox, C. D. 1986. Role of pyocyanin in the acquisition of iron from transferrin. Infect. Immun. 52:263-270.

26. Busch, C., P. A. Cancilla, L. E. DeBault, J. C. Goldsmith, and W. G. Owen. 1982. Use of endothelium cultured on microcarriers as a model for the microcirculation. Lab. Invest. 47:498.

27. Britigan, B. E., T. L. Roeder, and D. M. Shasby. 1992. Insight into the nature and site of oxygen-centered free radical generation by endothelial cell monolayers using a novel spin trapping technique. Blood. 79:699-707.

28. Britigan, B. E., T. J. Coffman, and G. R. Buettner. 1990. Spin trap evidence for the lack of significant hydroxyl radical production during the respiration burst of human phagocytes using a spin adduct resistant to superoxide mediated destruction. J. Biol. Chem. 265:2650-2656.

29. Ramos, C. L., S. Pou, B. E. Britigan, M. S. Cohen, and G. M. Rosen. 1992. Spin trapping evidence for myeloperoxidase-dependent hydroxyl radical formation by human neutrophils and monocytes. J. Biol. Chem. 267:8307-8312.

30. Bynoe, L. A., S. Pou, J. D. Gottsch, and G. M. Rosen. 1991. Light-dependent spin trapping of hydroxyl radical from human erythrocytes. Biochem. Biophys. Res. Commun. 179:1305-1310.

31. Bailar, J. C., Jr., and E. M. Jones. 1939. Trioxalato salts (trioxalatoaluminiate,-ferrate,-chromiate-cobaltiate). Inorg. Synth. 1:35-38.

32. Davis, G., and P. J. Thornalley. 1983. Free radical production from the aerobic oxidation of reduced pyridine nucleotides catalyzed by phenazine derivatives. Biochim. Biophys. Acta. 724:456-464.

33. Ishizu, Z., H. H. Dearman, M. T. Huang, and J. R. White. 1968. Electron paramagnetic resonance observations on biogenic semiquinone and 5-methyl phenazium radicals. Biochim. Biophys. Acta. 165:283-285.

34. Hassett, D. J., L. Charniga, K. Bean, D. E. Ohman, and M. S. Cohen 1992. Response of Pseudomonas aeruginosa to pyocyanin: mechanisms of resistance, antioxidant defenses, and demonstration of a manganese-cofactored superoxide dismutase. Infect. Immun. 60:328-336.

35. Morrison, M. M., E. T. Seo, J. K. Howie, and D. T. Sawyer. 1978. Flavin model systems. 1. the electrochemistry of 1-hydroxyphenazine and pyocyanine in aprotic solvents. J. Am. Chem. Soc. 100:207-211.

36. Hassan, H. M., and I. Fridovich. 1979. Intracellular production of superoxide radical and hydrogen peroxide by redox active compounds. Arch. Biochem. Biophys. 196:385-395.

37. Weinstein, J., and B. H. J. Bielski. 1979. Kinetics of the interaction of $\mathrm{HO}_{2}$ and $\mathrm{O}_{2}^{-}$radicals with hydrogen peroxide: the Haber-Weiss reaction. J. Am. Chem. Soc. 101:58-62.

38. Buettner, G. R. 1987. Spin trapping: ESR parameters of spin adducts. Free Radical Biol. Med. 3:259-303.

39. Rosen, G. M., and E. Finkelstein. 1985. Use of spin traps in biological systems. Adv. Free Radical Biol. Med. 1:345-375.

40. Pou, S., M. S. Cohen, B. E. Britigan, and G. M. Rosen. 1989. Spin trapping and human neutrophils: limits of detection of hydroxyl radical. J. Biol. Chem. 264:12299-12302.

41. Samuni, A., C. D. V. Black, C. M. Krishna, H. L. Malech, E. F. Bernstein, and A. Russo. 1988. Hydroxyl radical production by stimulated neutrophils reappraised. J. Biol. Chem. 263:13797-13801.

42. Rosen, G. M., B. E. Britigan, M. S. Cohen, S. P. Ellington, and M. J. Barber. 1988. Detection of phagocyte-derived free radicals with spin trapping techniques: effects of temperature and cell metabolism. Biochim. Biophys. Acto. 969:236-241.

43. Haber, F., and J. Weiss. 1934. The catalytic decomposition of hydrogen peroxide by iron salts. Proc. R. Soc. Lond. Math. Phys. Soc. 147:332-351.

44. Martin, W. J., II., J. E. Gadek, G. W. Hunninghake, and R. G. Crystal. 1981. Oxidant injury of lung parenchymal cells. J. Clin. Invest. 68:1277-1288.

45. Sacks, T., C. F. Moldow, P. R. Craddock, T. K. Bowers, and H. S. Jacob 1978. Oxygen radicals mediate endothelial cell damage by complement-stimulated granulocytes. An in vitro model of immune vascular damage. J. Clin. In vest. 61:1161-1167.

46. Weiss, S. J., J. Young, A. F. LoBuglio, A. Slivka, and N. F. Nimeh. 1981. Role of hydrogen peroxide in neutrophil-mediated destruction of cultured endothelial cells. J. Clin. Invest. 68:714-721.

47. Shasby, D. M., S. E. Lind, S. S. Shasby, J. C. Goldsmith, and G. W Hunninghake. 1985. Reversible oxidant-induced increases in albumin transfer across cultured endothelium: alterations in cell shape and calcium homeostasis. Blood. 65:605-614.

48. Shasby, D. M., S. S. Shasby, and M. J. Peach. 1983. Granulocytes and phorbol myristate acetate increase permeability to albumin of cultured endothelial monolayers and isolated perfused lungs: role of oxygen radicals and granulocyte adherence. Am. Rev. Respir. Dis. 127:72-76.

49. Gannon, D. E., J. Varani, S. H. Phan, J. H. Ward, J. Kaplan, G. O. Till, R. H. Simon, U. S. Ryan, and P. A. Ward. 1987. Source of iron in neutrophil-mediated killing of endothelial cells. Lab. Invest. 57:37-44.

50. Schellhorn, H. E., S. Pou, C. Moody, and H. M. Hassan. 1989. An electron spin resonance study of oxyradical generation in superoxide dismutase- and catalase-deficient mutants of Escherichia coli K-12. Arch. Biochem. Biophys. 271:323-331

51. Cohen, M. S., L. M. Charniga, M. J. Stutts, J. R. Yankaskas, D. J. Hassett, E. Krochmal, J. T. Gatzy, and R. C. Boucher. 1990. Effects of Pseudomonas pyocyanin on cystic fibrosis epithelial cells. Abstracts of the 30th Interscience Conference on Antimicrobial Agents and Chemotherapy. American Society for Microbiology, Washington, DC. 94. (Abstr.)

52. Rosen, G. M., and B. A. Freeman. 1984. Detection of superoxide generated by endothelial cells. Proc. Natl. Acad. Sci. USA. 81:7269-7273.

53. Rosen, G. M., D. J. Hassett, J. R. Yankaskas, and M. S. Cohen. 1989 Detection of free radicals as a consequence of dog tracheal epithelial cellular xenobiotic metabolism. Xenobiotica. 19:635-643.

54. Brown, M. R. W., H. Anwar, and P. A. Lambert. 1984. Evidence that mucoid Pseudomonas aeruginosa in the cystic fibrosis lung grows under iron restricted conditions. FEMS (Fed. Eur. Miobiol. Soc.) Microbiol. Lett. 21:113117

55. Haas, B., J. Kraut, J. Marks, S. C. Zanker, and D. Castignetti. 1991. Siderophore presence in sputa of cystic fibrosis patients. Infect. Immun. 59:39974000 .

56. Muller, M., and T. C. Sorrell. 1991. Effect of pyocyanin and 1-hydroxyphenazine on the assay of lactate dehydrogenase activity. J. Infect. Dis. 164:610 611 .

57. Amitani, R., R. Wilson, A. Rutman, R. Read, C. Ward, D. Burnett, R. A. Stockley, and P. J. Cole. 1991. Effects of human neutrophil elastase and Pseudo monas aeruginosa proteinases on human respiratory epithelium. Am. J. Respir. Cell Mol. Biol. 4:26-32.

58. Jackowski, J. T., Z. Szepfalusi, D. A. Wanner, Z. Seybold, M. W. Sielczak, I. T. Lauredo, T. Adams, W. M. Abraham, and A. Wanner. 1991. Effects of $P$ aeruginosa-derived bacterial products on tracheal ciliary function: role of $\mathrm{O}_{2}$ radicals. Am. J. Physiol. (Lung Cell. Mol. Physiol.) 260:L61-L67.

59. Miller, K. M., D. G. Dearborn, and R. U. Sorensen. 1987. In vitro effect of synthetic pyocyanine on neutrophil superoxide production. Infect. Immun 55:559-563.

60. Muller, P. K., K. Krohn, and P. F. Muhlradt. 1989. Effects of pyocyanine, a phenazine dye from Pseudomonas aeruginosa, on oxidative burst and bacteria killing in human neutrophils. Infect. Immun. 57:2591-2596.

61. Muller, M., and T. C. Sorrell. 1991. Production of leukotriene $B_{4}$ and 5-hydroxyeicosatetraenoic acid by human neutrophils is inhibited by Pseudo monas aeruginosa phenazine derivatives. Infect. Immun. 59:3316-3318.

62. Ulmer, A. J., J. Pryjma, Z. Tarnok, M. Ernst, and H.-D. Flad. 1990 Inhibitory and stimulatory effects of Pseudomonas aeruginosa pyocyanine on human T and B lymphocytes and human monocytes. Infect. Immun. 58:808815

63. Sorensen, R. U., J. D. Klinger, H. A. Cash, P. A. Chase, and D. G. Dearborn. 1983. In vitro inhibition of lymphocyte proliferation by Pseudomonas aeruginosa phenazine pigments. Infect. Immun. 41:321-330.

64. Nutman, J., M. Berger, P. A. Chase, D. G. Dearborn, K. M. Miller, R. L. Waller, and R. U. Sorensen. 1987. Studies on the mechanism of T cell inhibition by the Pseudomonas aeruginosa phenazine pigment pyocyanine. J. Immun 138:3481-3487.

65. Ras, G. J., R. Anderson, G. W. Taylor, J. E. Savage, E. Van Niekerk, R Wilson, and P. J. Cole. 1990. Proinflammatory interactions of pyocyanin and 1-hydroxyphenazine with human neutrophils in vitro. J. Infect. Dis. 162:178185 .

66. Muhlradt, P. F., H. Tsai, and P. Conradt. 1986. Effects of pyocyanine, a blue pigment from Pseudomonas aeruginosa, on separate steps of $\mathrm{T}$ cell activation: interleukin 2 (IL2) production, IL2 receptor formation, proliferation and induction of cytolytic activity. Eur. J. Immunol. 16:434-440.

67. Patel, K. D., G. A. Zimmerman, S. M. Prescott, R. P. McEver, and T. M McIntyre. 1991. Oxygen radicals induce human endothelial cells to express GMP-140 and bind neutrophils. J. Cell Biol. 112:749-759.

68. Lewis, M. S., R. E. Whatley, P. Cain, T. M. McIntyre, S. M. Prescott, and G. A. Zimmerman. 1988. Hydrogen peroxide stimulates the synthesis of plateletactivating factor by endothelium and induces endothelial cell-dependent neutrophil adhesion. J. Clin. Invest. 82:2045-2055.

69. Harlan, J. M., and K. S. Callahan. 1984. Role of hydrogen peroxide in the neutrophil-mediated release of prostacyclin from cultured endothelial cells. $J$. Clin. Invest. 74:442-448.

70. Tate, R. M., H. G. Morris, W. R. Schroeder, and J. E. Repine. 1984. 
Oxygen metabolites stimulate thromboxane production and vasoconstriction in isolated saline-perfused rabbit lungs. J. Clin. Invest. 74:608-613.

71. Welsh, M. J., D. M. Shasby, R. M. Husted, P. Karp, and P. Spory. 1985. Oxidants increase paracellular permeability in a cultured epithelial cell line. $J$. Clin. Invest. 76:1155-1168.

72. Winter, M., J. S. Wilson, K. Bedell, and D. M. Shasby. 1990. The conductance of cultured epithelial cell monolayers: oxidants, adenosine triphosphate, and phorbol dibutyrate. Am. J. Respir. Cell Mol. Biol. 2:335-363.

73. King, R. J., J. J. Coalson, J. J. Seidenfeld, A. R. Anzueto, D. B. Smith, and J. I. Peters. 1989. $\mathrm{O}_{2}^{-}$and pneumonia-induced lung injury. II. Properties of pulmonary surfactant. J. Appl. Physiol. 67:357-365.

74. Crim, C., and R. H. Simon. 1988. Effects of oxygen metabolites on rat alveolar type II cell viability and surfactant metabolism. Lab. Invest. 58:428-437.

75. Vercellotti, G. M., S. P. Severson, P. Duane, and C. F. Moldow. 1991 Hydrogen peroxide alters signal transduction in human endothelial cells. J. Lab. Clin. Med. 117:15-24.
76. Hiraishi, H., A. Terano, S. Ota, H. Mutoh, T. Sugimoto, M. Razandi, and K. J. Ivey. 1991. Oxygen metabolites stimulate mucous glycoprotein secretion from cultured rat gastric mucous cells. Am. J. Physiol. (Gastrointest. Liver Physiol.) 261:G662-G668.

77. Adler, K. B., W. J. Holden-Stauffer, and J. E. Repine. 1990. Oxygen metabolites stimulate release of high-molecular-weight glycoconjugates by cell and organ cultures of rodent respiratory epithelium via an arachidonic acid-dependent mechanism. J. Clin. Invest. 85:75-85.

78. Parker, N. B., E. M. Berger, W. E. Curtis, M. E. Muldrow, S. L. Linas, and J. E. Repine. 1985. Hydrogen peroxide causes dimethylthiourea consumption while hydroxyl radical causes dimethyl sulfoxide consumption in vitro. J. Free Radical Biol. Med. 1:415-419.

79. Britigan, B. E., and B. L. Edeker. 1991. Pseudomonas and neutrophil products modify transferrin and lactoferrin to create conditions that favor hydroxyl radical formation. J. Clin. Invest. 88:1092-1102. 